\title{
Performance as Philosophy - the universal language of the theatre revisited
}

\section{DANIEL MEYER-DINKGRÄFE \&}

\section{ANITA S. HAMMER}

\begin{abstract}
The history of philosophy is widely considered as the history of exercises in speculation. However, it is also possible to understand philosophy not as the outcome of speculation, but at the attempt by philosophers to explain, make sense of, and ultimately share, their own experiences of a very subtle, powerful and spiritual nature. The growing field of performance philosophy begins to acknowledge the potential of considering philosophy as an expression of immediate experience rather than distant speculation. This acknowledgement can take the shape of employing performance to express philosophy - in more immediately experienced ways than verbal language is ever able to convey. Writing about this non-verbal dimension is difficult, and the result limited by its very nature, but in this article, we discuss the principle, and provide an example in the performance philosophy, captured under the term of body thinking, of German philosopher and dancer Aurelia Baumgartner.
\end{abstract}

\section{KEYWORDS}

Performance philosophy, holistic, energy-paradigm, immediate experience, sensuous experience, imagination, consciousness studies. 


\section{Performance as Philosophy - the universal language of the theatre revisited}

\section{INTRODUCTION: DIALOGUE}

We have known each other as academic colleagues interested in similar aspects of our experiences in the theatre for a number of years, and over those years we have regularly shared the development of our thinking. When Nordic Theatre Studies published its call for submissions for its special issue on Theatre and Language, the time had come to take our ongoing dialogue a step further and seek to share our thoughts as dialogue with the readers of NTS. In all modesty, we are exploring for the 21st century the ancient Greek model of Plato's dialogues, adding the dimension that while, for Plato, the dialogue mode was the product of one author's (Plato's) thinking, who gave his words to both dialogue partners, in our case, there are two genuine partners and voices involved. In our dialogue, we also add the format of genuine exchange to the established convention of co-authored articles in the sciences where no individual section of the article is attributed explicitly to one of the co-authors. The experience of theatre comes into being through, and exists in, the dialogue of stage and spectators. Our dialogic performance on the page brings out insights that we would not have been able to create on our own. Perhaps our readers (as spectators) can share both the insights and the ways in which they came about and enter their own dialogue with ours.

\section{CONTEXT:}

\section{CONCRETE EXPERIENCE VERSUS ABSTRACT SPECULATION}

\section{Daniel Meyer-Dinkgräfe}

At its beginnings, across cultures, philosophy was a practical tool to enhance knowledge and, through that enhancement, increase well-being profoundly. Over time, philosophy has become restricted to the context of intellectual rea- 
soning, analysis and argument, devoid of the experiential component that was originally considered as an integral part of its nature. Philosophy is no longer based on practice, but theory alone, speculation. This shift of emphasis has led to philosophy losing its essential role in life, on the levels of both the individual and of society. I view the history of Western philosophy as a series of attempts by philosophers not at reasoned speculations, but at sharing with their readers, in the form of reasoned argument, the essence of their own experiences $^{1}$, for example: "Husserl (1859-1938) wrote that I, the meditating I, reduce myself to my absolute transcendental ego through the phenomenological epoché (Cartesian Meditations). Phenomenology was to be the discipline to study this new domain of the experience of pure transcendental consciousness. Epoché was a method of suspension of judgment in the mode of the natural standpoint, such that everything came to be understood as a phenomenon within consciousness, accessible by going within to analyse consciousness. 'I experience my own conscious existence directly and truly as it itself' (Paris Lectures). We direct the glance of [--] theoretical enquiry to pure consciousness in its own absolute being" (Ideas)."2

\section{Anita S. Hammer}

This may be a very generalised position, but let's start with it. It would perhaps be true to state that there has been a tendency in writings in the field of theatre studies, as well as generally in the fields of philosophy and the humanities, that the more abstracted from the experience itself, from its materiality and from its specifics, the higher the status and the publishing points of the writings.

\section{Daniel Meyer-Dinkgräfe}

But such abstractions can be a trap. The practice of writing itself may be a trap of language and a barrier of semantics rather than opening to a philosophy of performance that cannot grow through anything other than concrete, specific experience attained through the human senses. The recent revival of debate about the relationship between philosophy and performance was spearheaded initially within PSi, TaPRA, and IFTR and, while continuing in those umbrella organisations, is now located within its own dedicated organisation, Performance Philosophy. That debate has, at its core, the restoration of experience to philosophy by means of the practice of performance. This

2. Meyer-Dinkgräfe 2013b, 129. 
acknowledgement can take the shape of employing performance to express philosophy - in more immediately experienced ways than verbal language is ever able to convey.

\section{Anita S. Hammer}

It is this focus on the function of performance as philosophy - central, as you said, to Performance Philosophy - that is also central to our discussion. We want to tease out some further aspects of how performance can be more than "mere performance" and how performance can be philosophy. We should give some indication where we come from?

\section{Daniel Meyer-Dinkgräfe}

My research is anchored in consciousness studies, defined as the "the study of how we think, feel and act, why we think, feel and act as we do, and what it feels like to think, feel and act as we do." 3 From within consciousness studies, I focus further on positions of spirituality to provide explanatory contexts for phenomena of theatre and performance. I understand spirituality in a non-religious way, with the implication that "spirituality culminates in the full development of mind," and "any move in the direction of this fullness can be called spirituality."4

\section{Anita S. Hammer}

I find it interesting that you approach spirituality in an explanatory way. For myself, I am aware that my use of the concept of spirituality has been more of an approach in searching to find a way of describing aspects of experience of great importance that would otherwise have been left out. Now, you are also raising the question if spirituality may have something to do with religion? Yes, there may be spirituality in religious worship, but often that is spirituality gone wrong. Spirituality is about empowering the self, on the deepest levels. Religion is, so often, about structure and power. This is another big discussion, of course, and too far-reaching and important to be explored in the present context. But let me just say that I believe there is an urgent need for humans to take back their own spiritual individual power, as from their own experience, not letting themselves be reduced to non-spiritual beings, neither to let religious creeds steal their spirituality by imposing explanatory concepts that may in fact be distorting. Deploying spirituality itself as an explanatory context, as you suggest above, seems to be a good way of getting out of an

3. Daniel Meyer-Dinkgräfe 2013a, 11.

4. Malekin \& Yarrow 1997. 
old mess.

So, back to our argument - how can performance be philosophy - philosophy in action? There is a close connection between making general statements and those of a high level of abstraction. And in research, even in the humanities, and as can be seen also in the field of theatre studies, there is still a need to distance oneself from one's own experience, as if such experience is suspected of not being valid according to an unspoken norm of "objectivity", which has long since been consciously overridden during the history of research methods in the humanities, but which, nevertheless, still seems to be working ghost like in the shadows, depriving specific, personal and true experience of its validity. The steady need for abstraction, distance and general statements, with less importance given to the specific that is experienced through the senses, is continuing in the humanities, and in theatre studies specifically, due to a lack of will for research of the self, and how emotions, thinking, feeling and living are intertwined, also in the writings of philosophy. ${ }^{5}$

\section{Daniel Meyer-Dinkgräfe}

The writings of William James still hold ground in this context of continuing scepticism towards the subjective component of experience when he refers to science as being shallow, as long as the totality of experience is not considered: "The reason is that, so long as we deal with the cosmic and the general, we deal with only the symbol of reality, but as soon as we deal with private and personal phenomena, we deal with realities in the complete sense of the term".6

\section{Anita S. Hammer}

Another of the forefathers in the philosophy of the arts, John Dewey, has commented on the established cosmologies and theologies, which have held power over human imagination "through a direct appeal to the sense and sensuous imagination."7 Dewey strongly argues against isolating arts by "placing them in a realm of their own, disconnected from other modes of experiencing."8 The private and the personal, revealed through sensuous imagery shared as emerging experiences of meaning, now exist as a possibility in performative practices; opening up to viewing performance practices as a concrete act of philosophy.

\footnotetext{
5. Hammer 2010.

6. James 2002.

7. Dewey $1934,30$.

8. Dewey $1934,45$.
} 


\section{PERFORMANCE AND / AS EMBODIED PHILOSOPHY}

\section{Anita S. Hammer}

A more recent attempt at rendering philosophy more useful than it promises to be if taken as a set of speculations is the emergence of the concept of embodied philosophy. This can develop only through sensuous experience. What would be a better way of making philosophical ideas tangible than the creation of performative events that, in themselves, can embody what abstraction loses in its own process?

\section{Daniel Meyer-Dinkgräfe}

We will have to justify why older frameworks are still relevant while more recent ones need further contextualising because they are new and, if we are not careful, they are discounted outright as "esoteric".

\section{Anita S. Hammer}

Indeed, the point of justification needs to be addressed. In several fields in the humanities there have been arguments for the human mind and subjective experience to be considered in research, particularly influenced by the writings of Merleau-Ponty.

\section{Daniel Meyer-Dinkgräfe}

And there is transpersonal research methodology. ${ }^{9}$ But often Merleau-Ponty emphasis on "bodily experience" is understood as merely bodily - or it is considered, but overridden by other methods and approaches that are more evidential, and therefore considered to have a higher status.

\section{Anita S. Hammer}

As is very well known in our field of research, the twentieth century experiments of physical theatre (Artaud, Grotowski, Schechner) gained their inspiration from the practices of various eastern traditions of theatre and ritual. However, sometimes these practices got so embodied that they became closures rather than openings to the very ideas that they embodied. The postGrotowskian field of performance experiments is rich and varied, from the poorer than poor simplicity of Marina Abramovic to independent groups here in Scandinavia, established groups as different as Verdensteatret, Baktrup- 
pen, and SIGNA, but also more recent appearances, such as a dance production by Dreamscreen productions/Kristina Gjems ${ }^{10}$. Several of their works may in fact be seen as ways of transgressing sensuous boundaries exactly for this good reason, namely to penetrate the human experience in such a way that it awakens our senses to embodied ideas and ideals.

\section{EXAMPLES OF SCANDINAVIAN PERFORMANCE PRACTICE AND THEIR THEORETICAL CONTEXTUALISATION}

\section{Daniel Meyer-Dinkgräfe}

Can you elaborate on examples from Scandinavian performance practice?

\section{Anita S. Hammer}

In other contexts ${ }^{11}$ I have respectively described my reflections on the experiences of two such performative events - that of SIGNA's Seven Tales of Misery and of Verdensteatret's A Concert for Greenland. These two events differ, almost to the extreme, in their aesthetics, but nevertheless to me functioned as a trigger of awareness on several levels of consciousness. I have described my experience of Seven Tales of Misery as creating fluctuating states of awareness between individual and collective realms, allowing a confrontation with the fluctuation of my own consciousness, between individual independence, insecurity, and drive towards ritual surrender when focusing on personal experience as embodied philosophical experience. ${ }^{12}$

\section{Daniel Meyer-Dinkgräfe}

What kinds of theoretical contexts for this practice have you explored?

\section{Anita S. Hammer}

When experiencing Verdensteatret's performance of $A$ Concert for Greenland, I turned to the French philosopher Gaston Bachelard in order to find concepts by which to try to turn an intimate bodily and imaginative experience into writing. Bachelard, in his works, proposes the existence of a material imagination, a concept I consider helpful for the understanding of performance as philosophy. He points out the existence of images of matter, that is to say, imagery that is created directly from matter without which there is no possibi-

10. http://www.dansenshus.com/forestillinger/this-is-a-world-of-dew/

11. Hammer 2008 and Hammer 2007.

12. Hammer 2007. 
lity of gaining an understanding of how human imagination works. ${ }^{13}$ Bachelard opposes the existentialist's critical approach to imagination and replaces this with an approach to human imagination that celebrates it, and proposes human fantasy as a function of a vision into the future. To Bachelard, the experience of reality as materiality is the ground for all imagination; thus matter, emerging from bodily experience, is decisive to the quality of all imagination and sensation of matter present in human imagination. This has far-reaching epistemological consequences. Imagination is described as irreducible. This is because imagination emerges and is inseparable from bodily sensuous experience. When applied to the context of performance as philosophy, this means that the sensuous expression of the performer and all the other elements of performance, as well as the experience of the same by every member of the audience, are regarded as non-reducible subjective experience, and simultaneously as a shared experience of scenic imagined imagination. Their irreducibility makes them philosophical statements. "When forms, mere perishable forms and vain images - perpetual change of surfaces - are put aside, the images of matter are dreamt substantially and intimately. They have weight, they constitute a heart."14

\section{Daniel Meyer-Dinkgräfe}

Thus Bachelard's positions work best for you to make more sense of your experience of the performance?

\section{Anita S. Hammer}

In my experience of $A$ Concert for Greenland, I propose, with reference to Bachelard that the performance itself states a "Dreaming Consciousness" and the dialectics between inside and outside that Bachelard refers to as, "The two kinds of space. Intimate space and exterior space," here, "keep encouraging each other, as it were, in their growth." 15 In viewing performance as philosophy, all material elements may be considered as philosophy enacted by means of spatial imagination of matter. The quality of the materiality unfolding in the performance may be considered as constituting images of philosophy, irreducible and true to human experience.

13. Bachelard 1983, 2.

14. Bachelard 1983, 1.

15. Bachelard 1994, 201. 


\section{Daniel Meyer-Dinkgräfe}

In general, one may say that contemporary performance has, at its core, the levelling out of the hierarchy, which has canonised the semantics of language. Bodily expression, sound, light, movement and kinaesthetic, not giving itself over to reference to already accepted or presumed previous sensuous experience, is often at its core.

\section{Anita S. Hammer}

To take this further, some performances are, by the very sensuous experience that they reveal, actualizing experiences of what may be named "other realities". Such performances reveal dimensions of reality in which inner and outer dichotomies are on the verge of, or are being, dissolved. In some instances, these performances go to the core of the questioning of human sensuous experience and our idea of its limitation and possibilities. (See for instance Kim Skjoldager-Nielsen's description of the Islandic artist Olafur Eliasson's installation Your Blind Passenger. ${ }^{16}$ )

\section{PERFORMANCE PHILOSOPHY AS PRACTICE (1): ENERGY}

\section{Daniel Meyer-Dinkgräfe}

How can we let philosophical ideas penetrate our consciousness through the experience of performance?

\section{Anita S. Hammer}

It is simple, really, but hard to do. Human consciousness, on the immediate level, is contradictory. Therefore, we tend to leave out elements of reality that do not fit into previously accumulated ideas of it, and focus instead on those with which we are familiar, or by which our pre-understandings are not challenged. This is what in some contexts is referred to as "blocking" experience. If I go on doing this, my experience will be only partial, and I will not be able to put to use all those capacities that human consciousness has as its potential. Bodily presence of imagery that emerges from imagination rooted in matter, speaks directly to the whole of the human being in ways in which matter and mind cannot be separated. Neither can facts and non-facts, nor can inner or outer worlds. Performance that plays with imagery by means of the bodily and the sensuous, on a variety of levels or fields of experience, has the capacity

16. Skjoldager-Nielsen 2016 and https://www.youtube.com/watch?v=JhQqtNUIITY 
for uprooting blockages of pre-conditioning. Performance, seen in this way, functions as philosophy of ideas that, were it not for their embodiment, would not be visible.

\section{Daniel Meyer-Dinkgräfe}

How can ideas be expressed and created concretely and without abstraction?

\section{Anita S. Hammer}

Let me explain this by way of alignment to another subject field, namely, a comparison between western and eastern medical traditions. Western medicine has been built on the principle of cause and effect by understanding the bodily functions of a human being through using methods of research based on scientific evidence. Great achievements to human health have come from this. Eastern medicine, represented by ancient Chinese traditions as well as Indian traditions, represents a holistic approach. Chinese medicine proposes, for instance, that the meridians that run through our bodies are streams of life forces that not only can be found in the physical body, but also in additional "bodies" that are extended from these meridians both inwards, to the organs, as well as outwards, towards levels of energy in and around our bodies. Using both western and eastern approaches to medicine, a Norwegian doctor, Audun Myskja, proposes what he names an "energy paradigm".17 At the core of this paradigm is the understanding that the field of energy of a human being is not limited to the body, even if this energy field is situated in the body while we are alive. The energy paradigm, therefore, transgresses the body/mind boundary because all human emotion, thought, imagination, and experience, past and present, exist in these many-layered fields of energy in and around a human being, and express themselves in subtle or more articulate ways, according to their qualities.

\section{Daniel Meyer-Dinkgräfe}

This concept of the energy paradigm is very close to the concept of energy fields that I have discussed in terms of German geo-biologist Hans Binder's practical philosophy. As this is a new development in philosophy, I will spend some time to explain it. Across the universe, every manifestation can be considered as an energy field and each experience that we engage in is formed of a confluence of energy fields from past and present in the current moment in the current location in space. ${ }^{18}$ In her performances, Aurelia Baumgartner,

17. Myskja 2014-2016.

18. Meyer-Dinkgräfe 2013b, 105. 
who is a dancer with an MA in Philosophy and considers herself as a dancerphilosopher, seeks to lead the audience to an experience of philosophical contents. She calls it body-thinking. She exposes herself to a range of energy fields (in the form of concrete objects, contexts, ideas and associations) and then, guided by intuition, expresses the energy field that emerges from that confluence through her performance - performance in action. I will elaborate on her work further below.

\section{Anita S. Hammer}

Baumgartner's body-thinking seems to be a way of exploring various levels of individual, interactional and collective experiences. Imagery, as well as bodily sensation are integrated parts of such experiences in which they complete and enhance each other, even if considered contradictory to the logical mind. Therefore, knowledge of ourselves is available to us on many levels and in many shapes and forms, and in several dimensions, to the extent that we are willing to open our consciousness up to them. Saying this, I am aware that during the last decades, there have been many schematic representations of such philosophy delivered from ancient eastern sources and over to the west. But this has not really been working for western human beings. Why is this? This is because the western human being has the need to experience for herself the bodily energy fields, both her own and other fellow human beings' only then can this become a reality to her. It is, therefore, imperative to state that the energy paradigm is not an abstract model, but a way of opening up to experiences that are at the core of philosophical performance. Live on stage, philosophical performance, as such, will necessarily transgress all model thinking by appealing to trust in personal experience, considering it trustworthy and superior to speculation and abstraction.

Taking this into account when considering performance as philosophy, it is clear that engaging sensation by including the body, and extending bodily imagination by sound, rhythm, light and colour, and the space of the stage, can be no less than the ideal way of staging a philosophy that has human experience through the senses at its core, and that may pave the way for experiencing contradiction and conflict, oneness and diversity in oneself and in the other. This is because such performance is "experience" in the Dewey'an sense. 


\section{Daniel Meyer-Dinkgräfe}

Here the concept of embodiment helps considerably to make sense of concepts such as energy, which can come across as abstract as well, even if we are seeking to reduce abstraction in favour of something more concrete. It is through our bodies that we experience energy.

\section{PERFORMANCE PHILOSOPHY AS PRACTICE (2): IMAGINATION AND ARCHETYPES}

\section{Anita S. Hammer}

Imagination is at the core of embodied philosophy - imagination is created bodily - and goes through the mind again into the body for renewal in an everlasting spiral of life forces. Abstract philosophy does not have the advantage of taking us through such a process. But may not all appearance in the sensuous world serve this purpose, if humans are willing, not only performance? The answer is yes, but in the process of performance embodying philosophy we have, literally, a stage through (or "on") which we may take the opportunity to consciously be aware of our own consciousness and the way it works because we are made into consciously aware participants by the qualities embodied in the performance itself.

It may be timely here to remind ourselves of Victor Turner's etymological analysis of the word "performance" - from parfornuir (thoroughly furnish, making full [completion of]), ${ }^{19}$ and combine this with a quote from Bachelard: "If we cannot imagine we cannot foresee."20 Philosophical performance is about making philosophy fully human, as experience, in order to foresee who we really are.

\section{Daniel Meyer-Dinkgräfe}

The question has been raised, however, if such performative experiences may be considered as philosophical if they cannot reveal any general statements about the world that may be shared by many.

\section{Anita S. Hammer}

This is where the concept of archetypes comes in, another "old concept", perhaps, but one that still fulfils the purpose of adding to our understanding. The question arises whether all mythologies (regarded as the ancient language of

19. Turner 1982, 13-14.

20. Bachelard 1994, xxxiv. 
philosophy) share the same archetypes. When Jung spoke of archetypes, he did not speak of specific contents, but of structures/patterns existing in the human psyche in what he referred to as the "collective unconscious". He called these patterns archetypes because he identified these as having a tendency to shape typical, perhaps similar, or nearly identical contents in the collective artistic (philosophical) works of different cultures. The observation that content is different on surface levels is therefore no argument against the notion of archetypal patterns by itself.

Bachelard's descriptions of material imagination could not have been developed without reference to C.G. Jung. ${ }^{21}$ Jung was in no doubt that the various imagery-manifestations needed to be considered as precise and irreducible as possible. This means that images produced by the human mind can be seen for what they are rather than being taken as a "cover up" of hidden dangerous impulses of desire, as would be the case according to the psychoanalytical tradition. One may suggest that the reduction of images to fantasy (and thus untrue), and fantasy to nonsense, is due to the manifestations of human imagination not being taken seriously. In contrast, we argue that such images refer to extremely precise psychic realities and, if taken seriously, there is hardly any interpretation needed for understanding them. When I (with Bachelard), categorically state that no interpretation is needed, this is in order to underline the limits of the use of deduction or induction as well as hermeneutics of meanings as methods of interpreting imagery. Only if the mind can clear itself of the assumption that deductive or inductive interpretative processes are assumed when approaching imagery, can one get close to experiencing the image-forms. Jung puts it the following way: "The form, in fact, does not need any interpretation; it portrays its own meaning."22

From working with imagery in dreams, ethnographic material, and fantasy, Jung argued for the existence of "collectively existing, unconscious conditions." He thus proposes the method of "active imagination", whose purpose is not to trace imagery back to any prior figure, but to create a synthesis of passively existing contents of consciousness and unconscious influences. Jung described active imagination as a form of spontaneous amplification of archetypes. ${ }^{23}$ In his last work, published posthumously, Jung strongly emphasised the need for precision in the interpretation of "dreams and symbols."24 He warns us against turning these interpretations into a "mechanical system"

21. Bachelard 1994, xxxii.

22. Jung 1969, 90 (Hammer's translation).

23. Ibid.

24. Jung 1964a, 92. 
and then cramming them into "unimaginative brains." ${ }^{25} \mathrm{He}$ concludes: "One can explain and know only if one has reduced intuition to an exact knowledge of facts and their logical connections". ${ }^{26}$ Images reveal their contours as form. Amplification of these forms does not disturb or alter the form itself, but helps us see these contours more clearly.

\section{Daniel Meyer-Dinkgräfe}

To come to an understanding of the concept of archetypes and how to make it useful for the understanding of consciousness, the spectator must be rooted in experience, not in theory.

\section{Anita S. Hammer}

Archetypes are, according to Jung, irreducible images that do not appear as expressions of the personal psyche, but which rather express the collective cultural realm by spontaneously manifesting themselves in the cultural field. The most common approach to archetypes is to consider these images in terms of their contents. There is, however, a twofold difficulty in this approach. The first difficulty is the tradition of Jungian interpretations. Various specific content has somewhat "automatically" been ascribed to certain archetypes, solely based on content only, sometimes making us blind to the fact that these are emerging as form. This creates a difficulty in approaching the manifestations of archetypes altogether, since the term is so loaded with historically related manifestations of content. Archetypes are mythological images and mythologies can be archetypes. Regarding mythological contents, it is of importance, then, to consult with how Jung describes the notion of archetype. "It is necessary to point out once more that archetypes are not determined as regards their content, but only as regards their form, and then only to a very limited degree." 27 Jung bases this explanation on the position that these primordial images can only be determined when they get into the conscious realm of the psyche. Therefore, they can only be defined by the material that is conscious to the psyche, and that is by contents. This does not mean, however, that the "archetype" is identical to the "content". "Its form, however, [--] might perhaps be compared to the axial system of a crystal, which, as it were, performs the crystalline structure in the mother liquid, although it has no material existence of its own." 28 


\section{Daniel Meyer-Dinkgräfe}

I wonder, here, whether the Jungian approach to archetypes includes reference to the experience of the source of those archetypes on the level of the unconscious - in parallel, for example, to the position that the basis of all manifest content of consciousness, pure consciousness, is open to direct experience. This is the position held by Advaita Vedanta. Vedanta is one of the six orthodox schools of Indian philosophy, and within Vedanta, Advaita Vedanta is associated with the concept of non-dualism - the subjective monism that consciousness is all that exists.

\section{Anita S. Hammer}

The thought of such a possibility is inspiring. It also leads me to think of Rudolf Otto's notion of the numinos ${ }^{29}$ as the experience of spontaneous revelation as well as William James who, in his important work, refers to "religious experience", experiences that are "ineffable", and have "noetic qualities". ${ }^{30}$ I would rather refer to such experience, in this context, as "spiritual" - but again, as James points out, often set off by sensuous experience - and this could relate directly to experience of performance. Concerning Jungian archetypes, however, the discussion above leads me to the second difficulty, namely that trying to reveal the immaterial structure of archetypes would seem to be an impossible project, since these manifestations may only be available to consciousness through manifestation of contents. Jung proposes archetypes to be transgressive, meaning that they manifest across time/space in both psychic and physical spheres. ${ }^{31}$ Spontaneous amplification is a technique used in order to illuminate, or amplify archetypes appearing in personal as well as in cultural contexts. Returning to the energy-paradigm sketched above, the field of energy of a human being may be manifest through the structure of the energy field as well as through the imagination. Contents and form are then no longer separated. Contents may appear as form and form as contents, completing each other and describing manifestations on many levels of consciousness, pointing towards the archetypal in our lives. It may be argued, then, that such amplification is precisely what takes place in performances engaging body and mind in the way that, for instance, Aurelia Baumgartner's work exemplifies.

29. Otto 1959 (1923).

30. James 2002 (1902), 295.

31. http://www.terrapsych.com/jungdefs.html 


\section{PERFORMANCE PHILOSOPHY AS PRACTICE (3): CAST STUDY AURELIA BAUMGARTNER}

\section{Daniel Meyer-Dinkgräfe}

What you just described adds to our understanding of works of art, such as Baumgartner's. That is particularly the case when, in her intuitive way of working, Baumgartner finds herself inspired by myths and related archetypes, as for example in her work influenced by the Eurydice myth (see further below) and her work with horses, which also appear in mythology and have archetypal dimensions. For a 2012 performance, she presented a history of humanhorse interaction in several episodes, culminating in her pas-de-deux with her Arab Grey Pegasus. At the centre of her 2016 Dancing Horses - Different Others was the interaction of Pegasus with an autistic adolescent, an encounter between two individuals, one horse, one human, whose major mode of existence is fear. It was very striking to see how well those two interacted, overcoming fear.

\section{Anita S. Hammer}

Performance cannot perform archetypes by choice of contents, but by immersing the theatre makers and the spectators into a process that engages the participants and the recipients in such a many-layered way and on such a variety of levels that the archetypal structures open themselves to new contents and changing contents. This is, perhaps, at the core of how performance may be understood as philosophy.

\section{Daniel Meyer-Dinkgräfe}

The many-layered nature of Baumgartner's performance as philosophy is interesting in that context and the number of layers increases with each performance she creates. It is no longer merely dance, or merely choreography. This approach defies linearity and her performances go way beyond their contents, and require the spectator to open up to this ultimately new mode of creating.

Myths and archetypes have been considered as universal. Fischer-Lichte has considered the search for a universal language as one of the three components of intercultural theatre.32 Peter Brook and Suzuki Tadashi, for example, Fischer-Lichte argues, base their work on such a universal language of the theatre on archetypal and biological grounds. However, such a rea- 
soning is problematic. Recent research into myths, she argues, deny the archetypal aspect of myths. Research also suggests that although humans all over the world share the same basic needs, and behaviours, such as eating, sleeping, walking and standing, the ways in which those activities are carried out are culturally determined. ${ }^{33}$ Fischer-Lichte suggests several levels of theoretical discourse. The first implies the question as to what could be communicated in such a universal language of the theatre. The second level deals with the specific conditions that would enable a universal language of the theatre. The third level is the function of such a universal language of the theatre.

In this context I have argued that as long as we remain on the verbal level, because that is culture-specific, we are unable to reach the genuinely universal level - that of the language of nature (as Artaud put it). ${ }^{34}$ Just as much as philosophy can be understood not as a series of speculations, but as philosophers communicating and sharing their experience, performance can communicate from the universal level that is beyond verbal language; we can experience such performance first, and think about it later.

\section{Anita S. Hammer}

Can you elaborate more on Baumgartner as philosopher?

\section{Daniel Meyer-Dinkgräfe}

Aurelia Baumgartner's father, Hans Michael Baumgartner (1933-1999), was a highly respected professor of philosophy in Germany, and Baumgartner is a philosopher. Her work is philosophy, both what she has to say and what she does in her practice. In what she has to say, she has referenced the philosophers that she thinks about, thinks in terms of, and that have guided her thoughts. All that thinking is interwoven with her practice. For her, practice is thinking, and takes the shape of her performances. It is philosophy in practice, just as much as it is possible to understand the history of philosophy as practice - as the writings about personal experience. Philosophers encountered their own revelatory experiences and wrote about those experiences to make sense of them for themselves, and to share them with others to enable others to make sense of their own respective experiences, and to enable others to have the same, or a similar, experience. For many, the first encounter with such experiences was new, unexpected and life-changing. 


\section{Anita S. Hammer}

So Baumgartner's performances seek to bring philosophy back to the realm of experience, reclaiming them from the context of mere speculation?

\section{Daniel Meyer-Dinkgräfe}

I would say so. Perhaps she has found the key in performance that fine artists and musicians appear, or claim, to have found in their understanding of Practice as Research, which has left the restrictions of verbal language behind. Baumgartner's performance of Catch me if you can: Euridice 2012 Reloaded was presented on 11 June 2015 at the 6th International Conference on Consciousness, Theatre, Literature and the Arts at St Francis College, Brooklyn Heights, New York, and was developed into a performance installation for the 2015 annual conference of the Theatre and Performance Research Association (TaPRA); it is the first of her performances I want to discuss in the context of this article. ${ }^{35}$

The components of Eurydice interweave and interact, mediated from prepared audio and video material, and immediate components, unmediated through the live body on stage, and the arrangement of the live space. Module art adds to this diversity, which, despite, or, actually, because of the disparate nature of its components, coalesces into a whole that constitutes a new dimension. The performance moulds this new dimension and explores its facets, nuances and external textures. The formation of this new dimension is given to the recipient's experience - I am using this term because the term "spectator" is restricted to the visual and the term "audience" to the auditory senses. These terms do not do justice to the more comprehensive experience aimed at, enabled and taught by Eurydice. Either gradually, or in a sudden phase transition, the new dimension opens up to experience. While we know the sudden transition from the sudden shift that allows us, with Rubin's vase, for example, to see either a vase or two faces in profile, but never both at the same time, in Eurydice, in the new dimension, we are able to experience all aspects simultaneously. We can think and talk about this experience in academic terms, but that is not the same as the experience itself that we try to capture in this way. The performance has become embodied thinking, bodythinking, which is a more holistic way of experiencing the world - a performative idea of utopia.

35. Baumgartner 2016, 1-16. 


\section{Anita S. Hammer}

If only we could encounter the real world, whatever that is, in such a way. In that sense the performance, which we cannot grasp fully through words, has a didactic nature because the performance is not limited to the verbal "dimension". The nature of Baumgartner's performances, as you describe them, is such that they enable a philosophical experience in the recipient, and the performances are created in such a way that they intentionally and explicitly aim for that experience in their recipients. Any performance that does not have that intention and is "just a performance" may still trigger philosophical experiences, but would not count as "performance as philosophy" because it does not have the explicit intention of causing philosophical experience. There has to be an intention, and this intention is consciousness of consciousness, which can be experienced as a certain kind of "awareness", sometimes, and with regards to philosophy - awareness of ideas revealed.

\section{Daniel Meyer-Dinkgräfe}

Baumgartner's art is a good example of an art in which dance plays an important role, but which goes far beyond the traditional forms and structures of dance without denying, or ignoring them, and without reducing their current or past values. Through initial training and continued engagement with new material, intuition and openness for the world, interest and curiosity, together with hard work, Baumgartner has at her disposal a large pool of material to create from - it goes beyond dance forms across the world to include video art, module art and scenography as equal partners in the creative process. All these forms and aspects of art are enveloped and permeated by philosophical thinking. The variety goes against the linear, the telling of stories that can be retold and then, and thereby, ticked off. You will find less and less linearity in Baumgartner's work. Complexity increases instead, as does the multi-layered nature of her productions. The spaces are both physical by the way of miseen-scène and by the way of a spiritual horizon. The very multi-layered approach brings forth a new, higher, larger, and denser unity. The spectators can experience this unity if they are prepared to enter the adventure of these productions in an unprejudiced way and if they do not attempt to use their reason to find something linear, or to be able to understand something. It is a principle that is central to many spiritual traditions worldwide: the principle of "letting go".

Dancing Horses - Different Others was the performative video installation that Baumgartner presented on 29 January 2016 as part of the symposium 
BodyThinking in the context of the topic of Art and Inclusion. It is a project that seeks to bridge the boundaries of verbal language and linearity. We see video projections that constitute art, not mere documentation, through the camera, editing and sound. There are scenes of Baumgartner's pas-de-deux with her Arab Gray, Pegasus, and mare Mabrouka. A male flamenco dancer appears in a video and dances live on the stage, in front of the video screen, or in front of the empty screen. Three young female dancers dance together live; Baumgartner also dances live. In the video, we see an autistic adolescent, Christos Tsaoussidis, interact with Pegasus. Later, he comes onto the stage live joining in a scene with the three female dancers. He cues sounds and the dancers move in line with those sounds - they have learnt a sequence of movements for each sound and Tsaoussidis choreographs their movement through the cues he selects. There are further details that could be enumerated, relating to the stage, the dance, and the video. The details, how they may relate to each other, and whether we can make them fit through our intellectual analysis, are specifically not essential for the experience of this performance. The details merge into a holistic experience without any input from thinking, pondering, or rationalising - an experience that does not require the boundaries and limits of verbal language.

\section{CONCLUSION: MODES OF PERFORMANCE}

\section{Anita S. Hammer and Daniel Meyer-Dinkgräfe}

We have created a wide net in our conversation about the possibility of performance as philosophy, about the possibility that philosophy need not remain distant from human life as speculation. The main overarching focus was on embodiment, taking up a current trend that seems to want to reassure people that philosophy is comprehensible in a very concrete and tangible way for everyone, not only for a cerebral elite. We provided an analysis of concrete examples of performed philosophy / philosophical performance with reference to Scandinavian companies and productions, and with reference to the dance work of Aurelia Baumgartner, and discussed underlying principles and patterns at work in all of these examples with reference to the concepts of energy and image and archetypes. The sequence in which we presented this material led from the abstract (philosophy understood as speculation) to the concrete (philosophy understood as experience that can be enabled or achieved in or through performance) and, via further substantiation of the concrete (Scandinavian performance examples), to more abstract considerations 
(energy, image and archetype) and ended with the concrete (Baumgartner's work). In this way, not only the contents of our dialogue, but also its alternation of abstract and concrete represent written aspects of a performance of philosophy.

\section{References}

Anderson, Rosemarie \& William Braud. 2011. Transforming Self and Others Through Research: Transpersonal Research Methods and Skills for the Human Sciences and Humanities. Albany: SUNY Press.

Bachelard, Gaston. 1983. Water and Dreams: An Essay on the Imagination of Matter. Dallas: The Pegasus Foundation, Dallas.

Bachelard, Gaston. 1994. The Poetics of Space. Boston: Beacon Press.

Baumgartner, Aurelia. 2016. "'Catch me if you can!' -Eurydice 2012

Reloaded: Notes on the Performance", in Daniel Meyer-Dinkgräfe (ed.).

Consciousness, Theatre, Literature and the Arts 2015, Cambridge Scholars

Publishing, Newcastle, 1-16.

Chalquist, Craig. N.d. A Glossary of Jungian Terms. Online at http://www.terrapsych.com/jungdefs.html. accessed 18 September 2016.

Dewey, John. 1934. Art as Experience. New York: Pedigree.

Fischer-Lichte, Erika. 1989. "Das Theater auf der Suche nach einer Universalsprache." Forum Modernes Theater 4:2, 115-21.

Hammer, Anita. 2007. "Exploring Ritual Dynamics by Means of Fiction: The Non-Ethics of the Inbetween", in Daniel Meyer-Dinkgräfe (ed.).

Consciousness, Literature and the Arts 2007. Newcastle: Cambridge

Scholars Publishing, 134-155.

Hammer, Anita. 2008. "Theatre as Event of Material Imagination Materialized." Consciousness, Literature and the Arts 9:3.

Hammer, Anita. 2010. Between Play and Prayer: The Variety of Theatricals in Spiritual Performance. Amsterdam: Rodopi.

James, William. 2002. The Varieties of Religious Experience. London:

Routledge

Jung, Carl Gustav. 1969. Psykens Verden. Oslo: Cappelen.

Jung, Carl Gustav. 1964a. Man and His Symbols. London: Aldus Books.

Jung, Carl Gustav. 1964b. The Archetypes and the Collective Unconscious.

Bollingen Series XX. Princeton: Princeton University Press. 
Malekin, Peter and Ralph Yarrow. 1997. Consciousness, Literature and Theatre: Theory and Beyond. London: MacMillan.

Meyer-Dinkgräfe, Daniel. 2005. Theatre and Consciousness: Explanatory Scope and Future Potential. Bristol: Intellect.

Meyer-Dinkgräfe, Daniel. 2013a. Theatre, Opera and Consciousness: History and Current Debates, Rodopi, Amsterdam, 2013.

Meyer-Dinkgräfe, Daniel. 2013b. Observing Theatre: Spirituality and Subjectivity in the Performing Arts. Amsterdam: Rodopi

Myskja, Audun. 2014-16. A series of lectures and exercises at Senter for livshjelp, Ski, Norway.

Otto, Rudolf. 1959. The Idea of the Holy. London: Penguin Books.

Skjoldager Nielsen, Kim. 2016. "Über die Schwelle, in die Welt hinein. Das spirituelle Potential der Performance." ("Across the Threshold, Into the World. The Spiritual Potential of Performance") double - magazin für puppen- figuren- und objekttheater No. 33 and https://www.youtube.com/watch?v=JhQqtNUIITY

This is a world of dew. Kristina Gjems. Premiere: 19.5.2015, Danses Hus, Oslo. http://www.dansenshus.com/forestillinger/this-is-a-world-of-dew/

Turner, Victor. 1982. From Ritual to Theatre. New York: PAJ Publications.

\begin{abstract}
AUTHORS.
Daniel Meyer-Dinkgräfe studied English and Philosophy at the Universität Düsseldorf. In 1994 he obtained his Ph.D. from the University of London. From 1994 to 2007, he was Lecturer and Senior Lecturer in the Department of Theatre, Film and Television Studies, University of Wales Aberystwyth. Since October 2007 he has been Professor of Drama at the Lincoln School of Performing Arts, University of Lincoln. He has numerous publications on the topic of Theatre and Consciousness to his credit, and is founding editor of the peer-reviewed web-journal Consciousness, Literature and the Arts and the book series of the same title with Brill I Rodopi.
\end{abstract}

Anita S. Hammer studied Theatre, Literature and Nordic Language at the Universities of Trondheim and Bergen. She has worked with mythology, creative writing, acting and storytelling in Norway and New Zealand. Her Ph. D, in Theatre Studies was obtained from the Norwegian University of Science and Technology in 2001. She was a Professor/associate Professor of Theatre Studies at the University of Oslo from 2002 to 2011. Since 2011 she has been a Professor at the Queen Maud University College in Trondheim. She works actively to combine aesthetic academic approaches with holistic practices. She has published books and articles on the topic of theatre and spirituality, and has a special interest in ritual practice and theory, and performance theory. She has been connected to the network of Consciousness, Literature and the Arts since 2006. 